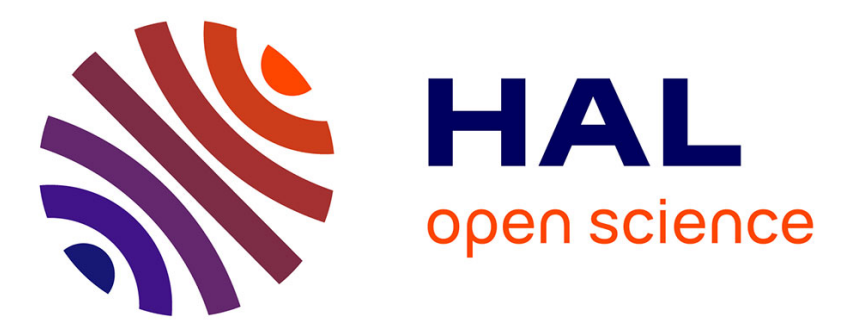

\title{
Detection of deviations origins in a heat treatment process using Proper Orthogonal Decomposition (POD) basis
}

Laurent Vanoverberghe, Lucia Garcia-Aranda, David Ryckelynck, Yvan

Chastel

\section{To cite this version:}

Laurent Vanoverberghe, Lucia Garcia-Aranda, David Ryckelynck, Yvan Chastel. Detection of deviations origins in a heat treatment process using Proper Orthogonal Decomposition (POD) basis. 11th ESAFORM Conference on Material Forming, Apr 2008, Lyon, France. pp.Pages 1055-1058, 10.1007/s12289-008-0200-3 . hal-00391672

\section{HAL Id: hal-00391672 \\ https://hal.science/hal-00391672}

Submitted on 19 Aug 2010

HAL is a multi-disciplinary open access archive for the deposit and dissemination of scientific research documents, whether they are published or not. The documents may come from teaching and research institutions in France or abroad, or from public or private research centers.
L'archive ouverte pluridisciplinaire HAL, est destinée au dépôt et à la diffusion de documents scientifiques de niveau recherche, publiés ou non, émanant des établissements d'enseignement et de recherche français ou étrangers, des laboratoires publics ou privés. 


\title{
Detection of deviations origins in a heat treatment process using Proper Orthogonal Decomposition (POD) basis
}

\author{
L. Vanoverberghe ${ }^{1,2}$, Lucia Garcia-Aranda ${ }^{1}$, David Ryckelynck ${ }^{3}$, Yvan Chastel $^{2}$ \\ ${ }^{1}$ Renault - 67 rue des Bons Raisins, 92500 Rueil-Malmaison, France \\ URL: www.renault.com \\ e-mail: laurent.vanoverberghe@renault.fr; \\ lucia.garcia-aranda@renault.com
}

${ }^{2}$ Centre de Mise en Forme des Matériaux, CEMEF (ENSMP) - 1 rue Claude Daunesse, 06904 Sophia-
Antipolis, France
URL: $\underline{\text { http:/ } / w w w-c e m e f . c m a . f r} \quad$ e-mail: yvan.chastel@ensmp.fr

${ }^{3}$ Centre des Matériaux (ENSMP) -

ABSTRACT: It is well know that the heat treatment step of gearbox cogwheel induces distortions of the parts. In addition, some deviations of this deformation are often observed, due to unknown changes of process parameters. These deviations, and more precisely the detection of their origin, are the subject of this paper. We propose here a methodology based on the projection of measurements after heat treatment on a POD (Proper Orthogonal Decomposition) basis, extracted from FEM computations. This information about deviation origin can help correct incriminated process parameters.

Key words: Heat treatment, Gear, Distortion, Proper Orthogonal Decomposition basis, Model reduction

\section{INTRODUCTION}

Many articles ([1, 2], etc.) have shown POD (Proper Orthogonal Decomposition, also called KarhunenLoeve expansion or Principal Component Analysis) method can help identify a shape. This method is used in this study to identify a deformation after heat treatment and to correlate it with a type of variation.

In a previous article (see [3]), numerical simulations were performed to show that heat transfer coefficient, quenching temperature and carbon layer features have a major effect on deformation. This work focuses on the boundary conditions and their impact on distortions.

First a set of nominal boundary conditions is defined to represent a nominal heat treatment process. Next, a POD of the FEM temporal solution is carried out to extract a POD basis of displacements. Taking into account all the displacements history, a more physical meaning of the eigenvectors is obtained (one or more vectors for dilatation for example). This basis is completed with other FEM computations for different boundary conditions. Directions are defined in the POD basis, each one linked to a variation of process parameter. Moving along a direction means that changes observed are caused by the parameter variation.

In parallel, other computations are carried out for different boundary conditions. The final results of these simulations are projected on the directions previously defined. Major component gives a paramount directions and so a variation of process parameter.

To make measurements simple, tubular samples with different bores are used (Fig. 1). Important variations in the bore diameters are defined in order to cause large final distortions (see [4]).
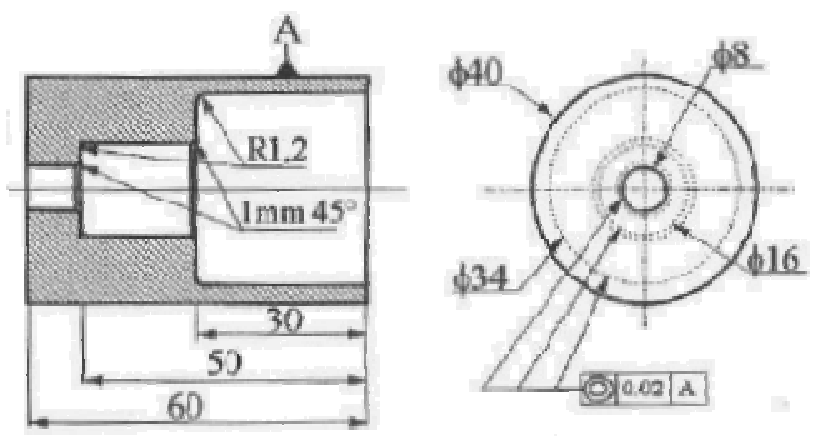

Fig. 1: Sample (from [4])

The heat treatment process (heating and carburizing followed by quenching) is simulated in 2D using the software Sysweld. We focus in this work on variations of carbon layer concentration, on 
quenching temperature and heat transfer coefficient. Variations of these parameters are presented here and the other ones (CCT diagrams, mechanical model, etc.) are kept the same for all simulations.

\section{THE DECOMPOSITION}

As the problem under investigation has a convenient number of degrees of freedom, a classic Snapshot POD [5] is used to find the POD vectors.

All the displacements at each time step $\underline{q}_{t}$ are placed in a same matrix $Q$. First, the covariance matrix is calculated:

$\underline{\underline{C}}=\underline{\underline{Q^{T}}} \underline{\underline{Q}}$

Eigenvalues and eigenvectors (matrix $\underline{\underline{V}}$ ) of this matrix are computed. Only eigenvectors with meaningful eigenvalues are taken into account. POD basis is given by:

$\underline{\underline{\Psi}}=\underline{\underline{Q V}}$

Each column of $\underline{\underline{\Psi}}$ is a POD vectors

The coefficients $\underline{\underline{\Phi}}$ of these vectors are given by:

$\underline{\underline{\Phi}}=\underline{\underline{\Psi}} \underline{\underline{Q}}$

Initial displacements $Q$ can be recovered with:

$\underline{\underline{Q}}=\underline{\underline{\Psi}} \underline{\underline{\Lambda}} \underline{\underline{\Phi}}^{T}$

where $\underline{\underline{\Lambda}}$ is the identity matrix.

\section{THE NOMINAL COMPUTATION}

A set of nominal values of the boundary conditions is defined.

\subsection{Carbon layer depth}

The carburizing computation is performed with a carbon activity of 0.95 . We obtain a maximum value of mass carbon concentration [C] of $0.87 \%$ at the sample corners.

\subsection{Quenching temperature}

Nominal quenching temperature is $50^{\circ} \mathrm{C}$. The quenching lasts 610 seconds. It is followed by an air-cooling to reach a temperature of $25^{\circ} \mathrm{C}$ in the part.

\subsection{Heat transfer coefficient}

Heat transfer coefficient $h$ is considered as constant $\left(1500 \mathrm{~W} / \mathrm{m}^{2} / \mathrm{K}\right)$ on all surfaces.

\section{THE PERTURBED COMPUTATIONS}

Simulations are performed for the set of parameters defined in Table 1.

Table 1. Changes in boundary conditions to create the basis

\begin{tabular}{|lr|l|}
\hline Parameter & & Values applied \\
\hline Carbon activity & {$[-]$} & $0.85,0.9,1,1.05$ \\
Heat transfer coefficient & {$\left[\mathrm{W} / \mathrm{m}^{2} / \mathrm{K}\right]$} & $1350,1425,1525,1550$ \\
Quenchant temperature & {$\left[{ }^{\circ} \mathrm{C}\right]$} & $40,45,55,60$ \\
\hline
\end{tabular}

Therefore the number of computations is the following: a nominal computation and twelve perturbed computations. Note that for heat transfer coefficient, only the heat transfer of the lower face $\left(h^{*}\right)$ is modified, as shown in Fig. 2. This would represent a modification of the quenchant media circulation for example.

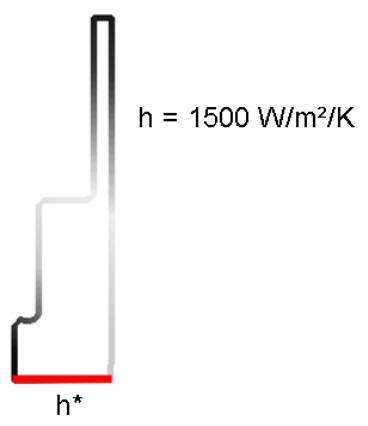

Fig. 2 : Heat transfer coefficient used for perturbed computations

\section{THE POD BASIS CONSTRUCTION}

The goal is then to create a basis and a direction related to a change of boundary conditions. Emphasis is placed on comparisons with results of the nominal set. So it is relevant to create two POD bases: a "recurrent" one, which contains all common eigenvectors, and another "specific" one, with eigenvectors which are dedicated to the variations.

The nominal and perturbed computations are used to create the POD basis. Matrix $Q$ contains all displacements at each time step and for each case:

$\underline{\underline{Q}}=[\underbrace{\underline{q}_{t_{i}}^{B C_{1}} \cdots \underline{q}_{t_{f}}^{B C_{1}}}_{\text {Simulation } 1} \cdots \underbrace{\underline{q}_{t_{i}}^{B C_{n}} \cdots \underline{q}_{t_{f}}^{B C_{n}}}_{\text {Simulation } n}]$

Simulation 1 is the nominal case.

After performing the decomposition described in section 2 , we obtain a matrix $\underline{\underline{\Psi}}$ with all eigenvectors 


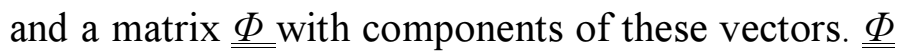
has the same structure as $Q$.

A coefficient $\gamma_{j}^{B C k}$ representing the "intensity" of an eigenvector $j$ for a simulation $k$ is defined:

$\gamma_{j}^{B C_{k}}=\sqrt{\sum_{i}\left(\Phi_{j i}^{B C_{k}}\right)^{2}}$

An eigenvector $j$ is considered as specific if the following condition is fulfilled:

$\min _{k} \gamma_{j}^{B C_{k}}<\alpha \max _{k} \gamma_{j}^{B C_{k}}$

where $\alpha$ is a parameter to be determined.

\section{DEFINITION OF THE DIRECTIONS}

Once the specific POD basis $\underline{\underline{\Psi}}$ has been determined, the directions correlated to a change of boundary conditions have to be defined.

Matrix $Q$ is again projected but this time on the specific basis, to provide specific coefficients $\underline{\underline{\Phi}}$, which fit best the results $Q$.

For each perturbed simulation, difference between its projection and the nominal projection is used to create the direction in which the simulation moves in the specific basis. The projection variation is:

$\underline{\underline{\Delta \Phi}}_{s}^{B C_{k}}=\frac{\underline{\underline{\Phi}}_{s}^{B C_{k}}-\underline{\underline{\Phi}}_{s}^{B C_{1}}}{\Delta B C_{k}}$

where $\triangle B C_{k}$ is a weight attributed to the boundary conditions change.

The components of the direction related to the change in boundary conditions $\triangle B C_{k}$ are computed by:

$$
\delta_{j}^{B C_{k}}=\sqrt{\sum_{i}\left(\Delta \Phi_{s j i}^{B C_{k}}\right)^{2}}
$$

The set of all these directions form the matrix $\underline{\underline{\delta}}$. The matrix $\underline{\underline{\delta}}^{\mathrm{T}} \cdot \underline{\underline{\delta}}$ shows the coupling between each direction. A high coupling means that directions are nearly similar and can not provide a unique information on a variation.

\section{IDENTIFICATION OF CHANGE IN BOUNDARY CONDITIONS}

Directions of some changes of boundary conditions have been defined. If some new perturbed results are projected on these directions, the major components will give the probable cause of the variation. The goal is to project the final result of the computation or of an experimental measurement.

Let us investigate in detail the projection of the final state. The variation of this projection is computed as in equation 8 but only with the final displacement $\underline{\Phi}_{t f}$ (a column vector):

$\underline{\Phi}_{t_{f}}=\underline{\Phi}_{t_{f}}-\underline{\Phi}_{t_{f}}^{B C_{1}}$

This variation is projected on the directions contained in the matrix $\underline{\underline{\delta}}$ :

$\underline{\underline{p}}=\underline{\underline{\delta}}^{T} \underline{\Delta \Phi}_{t_{f}}$

Each column of $\underline{p}$ gives the components of the variation on the directions previously computed. A direction will be considered as paramount if the absolute value of its component is strictly superior to $90 \%$ of the absolute value of the maximal component. This paramount direction provides information about the change of boundary conditions.

\section{APPLICATION OF THE METHOD}

One creates a basis able to recognize three types of variations: carbon layer concentration, quenching temperature and heat transfer coefficient.

Of course, the parameters $\alpha$ (see equation 7 ) needs to be tuned to define the separation between recurrent and specific basis. One computes the dimension of the specific basis and maximum coupling between directions as a function of $\alpha$ (Fig. 3)
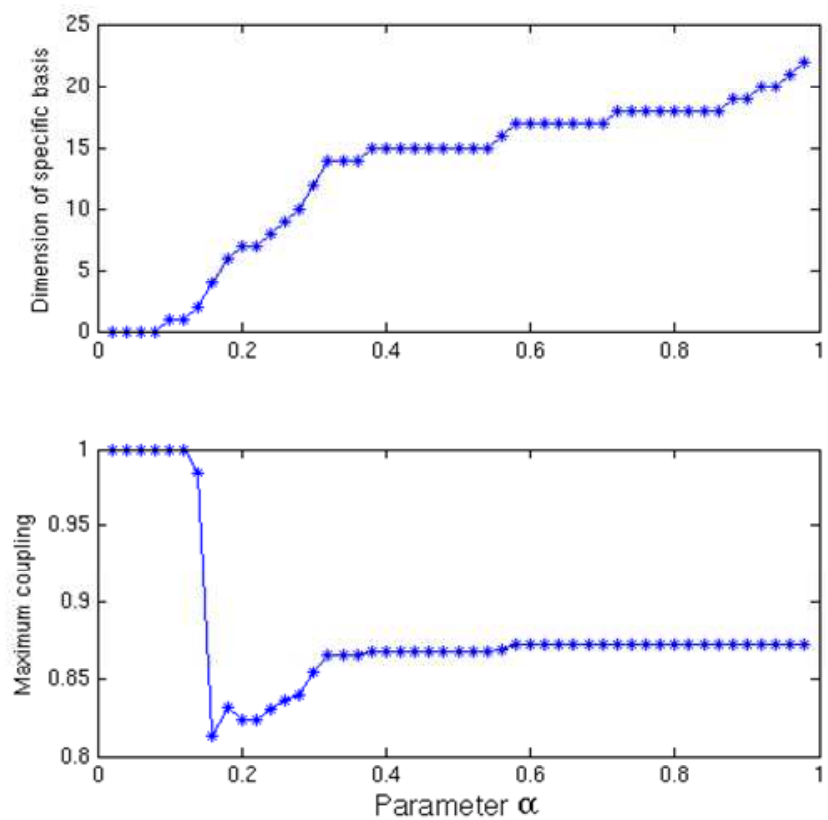

Fig. 3: Evolution of the specific basis dimension and of the maximum coupling of directions with alpha

The best results are obtained when coupling is 
minimum but in association with an adequate number of specific POD vectors. In our case, the best detection of the variation occurs with a value for parameter $\alpha$ of 0.17 .

Fig. 4 shows examples of POD vectors which were determined. Some of them can obviously be linked to physical phenomena (for example, the first one is a dilatation mode) but the major part represents an arbitrary deformations.
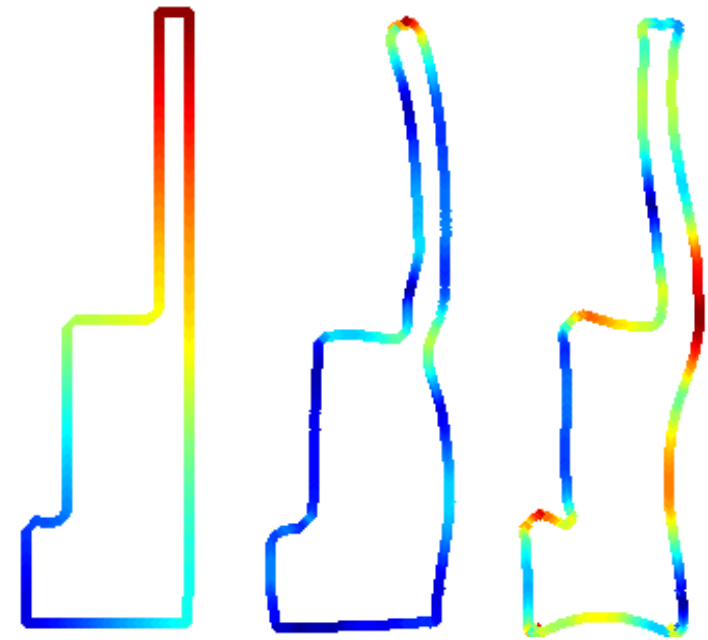

Fig. 4: Examples of normalized POD vectors (colours are function of the displacement norm).

In a first step, the final displacements of the 12 perturbed computations are projected on the three directions. In this case, one could expect a good detection since the same simulations results were used to create the basis. A really promising result is obtained: 10 variations are identified, one is undetermined and only one is false.

In a second step, 6 other simulations were carried out, with the variations defined in Table 2 .

Table 2. Changes in boundary conditions to detect

\begin{tabular}{|lr|l|}
\hline Parameter & & Values applied \\
\hline Carbon activity & {$[-]$} & $0.8,1.1$ \\
Heat transfer coefficient & {$\left[\mathrm{W} / \mathrm{m}^{2} / \mathrm{K}\right]$} & 1175,1725 \\
Quenchant temperature & {$\left[{ }^{\circ} \mathrm{C}\right]$} & 35,65 \\
\hline
\end{tabular}

The projection of the final displacements on the basis leads to successful identifications of 5 variations, one being undetermined.

This result is excellent since this final displacement is nearly similar for all the computations (see Fig. 5). Furthermore, only displacements on the external surface are used. If one restricts to points of external diameter, the results are nearly as good (4 correct identifications and 2 errors).

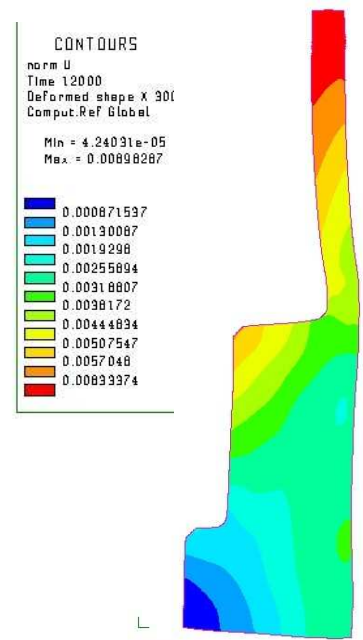

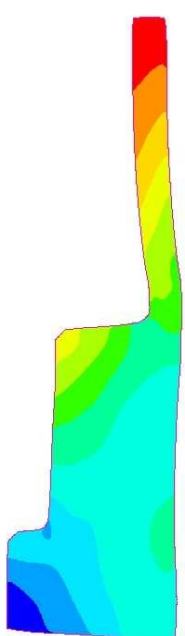

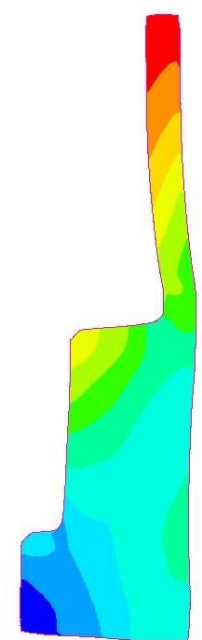

Fig. 5: Final displacements of three simulations (a: carbon activity of 0.8 ; b: heat transfer coefficient of $1725 \mathrm{~W} / \mathrm{m}^{2} / \mathrm{K}$ on lower surface ; c: quenching temperature is $65^{\circ} \mathrm{C}$ ). The scale is the same for the three figures.

\section{CONCLUSIONS AND PERSPECTIVES}

This method seems to be promising since a source of variations can be detected with the mere projection of a final displacement on a numerical POD basis. Once the major deviations are identified and correlated with simulations, the creation of the basis is quite simple. An important point here is that the correlation can only be qualitative and not quantitative.

In future works, experimental measurements will be projected on the POD basis, for the same sample. Finally, applications to tooth gear shape will be considered.

\section{REFERENCES}

1. Grigoriev, A. Ya. and Chizhik, S. A. and Myshkin, N. K., Texture classification of engineering surfaces with nanoscale roughness, Int. J. Mach. Tools Manufact., Vol. 38 (1998) 719-724.

2. Pinowski B., Principal component analysis of speech spectrogram images, Pattren recognition, Vol. 30 (1997) 777-787.

3. Vanoverberghe, L. and Garcia-Aranda, L. and Ryckelynck, D. and Chastel Y., Anticipation of gears distortions during heat treatment, 10th International Conference on Material Forming (Esaform), Zaragoza (2007).

4. Lasserre, R. and Henault, E., Une méthodologie d'étude des deformations lors $\mathrm{du}$ traitement thermique : l'éprouvette de deformation, In: Proc. Journées francoallemandes ATTT-AWT, Belfort (1997) 26-30.

5. Sirovich, L., Turbulence and the dynamics of coherent structures. Part 2: Symmetries and transformations. Part 3: Dynamics and scaling. Quartely of Applied Mechanics 45 (1987) 561-590. 